\title{
Homemade proximal scalloped stent graft for thoracic endovascular aortic repair of zone 2 acute aortic syndrome
}

\author{
Ludovic Canaud, MD, PhD, Thomas Gandet, MD, Ilya Khantalin, MD,
}

Baris Ata Ozdemir, MBBS, BSc, MRCS, Charles-Henri Marty-Ané, MD, PhD, and Pierre Alric, MD, PhD

\begin{abstract}
Objective: The aim of this study was to evaluate the outcomes of homemade proximal scalloped stent grafts for thoracic endovascular aortic repair of zone 2 acute aortic syndrome.

Methods: Between May 2015 and December 2015, 10 patients with unremitting symptoms or rupture secondary to an acute aortic syndrome involving zone 2 underwent urgent or emergency thoracic endovascular aortic repair. Among them, 8 were treated using homemade proximal scalloped stent grafts to preserve the patency of the left subclavian artery. Indications included traumatic transection $(\mathrm{n}=3)$ and acute $(\mathrm{n}=4)$ and subacute $(\mathrm{n}=1)$ complicated type B aortic dissection. Follow-up computed tomography scans were performed at 1 week and 3 and 6 months.
\end{abstract}

Results: The median duration for stent graft modification was 15 minutes (range, 14-17 minutes). The technical success rate was 100\%; sealing was achieved in all cases with no type I endoleaks. All left subclavian arteries were patent, although 1 case was associated with a $50 \%$ stenosis. No deaths occurred as a consequence of the aortic repair, but 1 patient died of a traumatic renal hematoma on postoperative day 5. During a mean follow-up of $7.2 \pm 2$ months, there were no conversions to open surgical repair, aortic ruptures, paraplegia, retrograde dissection, or other aortic complications.

Conclusions: The use of the homemade proximal scalloped stent graft is both feasible and effective for left subclavian artery revascularization during thoracic endovascular aortic repair involving a spectrum of acute thoracic aortic pathology. This approach provides a rapid, reproducible method of scalloping the endograft. Durability concerns will need to be assessed in additional studies with long-term follow-up. (J Thorac Cardiovasc Surg 2016;152:1301-6)

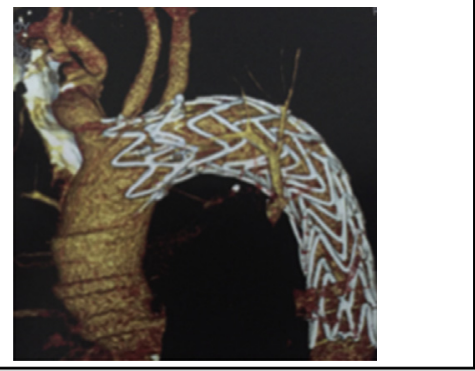

Patient treated by homemade scalloped TEVAR with proximal scallop for the LSA.

\section{Central Message}

The use of a homemade proximal scalloped stent graft is both feasible and effective for LSA revascularization during TEVAR involving a spectrum of acute thoracic aortic pathology.

Perspective

The use of a homemade proximal scalloped stent graft is both feasible and effective for LSA revascularization during TEVAR involving a spectrum of acute thoracic aortic pathology. This approach provides a rapid, reproducible method of scalloping the endograft. Durability concerns will need to be assessed in additional studies with long-term follow-up.

See Editorial Commentary page 1307.

See Editorial page 1229.
Traditional management of acute aortic syndrome includes open surgical replacement of the thoracic aorta and is associated with a high perioperative mortality and morbidity. Endovascular repair of aortic pathology increasingly is being used as an alternative to open surgery.

A recent article on emergency endovascular repair of acute aortic syndromes reported a left subclavian artery

\footnotetext{
From the Department of Thoracic and Vascular Surgery, Arnaud de Villeneuve Hospital, Montpellier, France.

Received for publication March 23, 2016; revisions received April 29, 2016; accepted for publication May 24, 2016; available ahead of print June 16, 2016

Address for reprints: Ludovic Canaud, MD, PhD, Service de Chirurgie Vasculaire et

Thoracique, Hôpital A de Villeneuve, 191 av Doyen Gaston Giraud, 34090 Montpellier, France (E-mail: ludoviccanaud@ hotmail.com).

$0022-5223 / \$ 36.00$

Copyright (c) 2016 by The American Association for Thoracic Surgery

http://dx.doi.org/10.1016/j.jtcvs.2016.05.025
}

(LSA) coverage rate of $84.3 \% .^{1}$ Intentional stent graft coverage of the LSA initially was thought to be a viable alternative in this setting to extend the applicability of thoracic endovascular aortic repair (TEVAR). Experience with intentional LSA coverage without revascularization unfortunately has demonstrated a significant association with spinal cord and left upper limb ischemia, as well as vertebral territory stroke. ${ }^{2,3}$

Scanning this QR code will take you to the article title page. 


\section{Abbreviations and Acronyms}

LSA $=$ left subclavian artery

TEVAR $=$ thoracic endovascular aortic repair

Reports of procedures that maintain the patency of the LSA include debranching before elective TEVAR, ${ }^{4}$ the chimney technique of deployment of a LSA stent parallel to the thoracic stent graft, ${ }^{5}$ and retrograde laser fenestration. ${ }^{6}$

The purpose of the following study was to review our experience with homemade proximal scalloped stent grafts for TEVAR of zone 2 acute aortic syndrome.

\section{MATERIALS AND METHODS \\ Patients}

Protocol and informed consent were approved by the institutional review board. This experience with homemade proximal scalloped stent grafts started in May 2015. Consecutive patients with zone 2 acute aortic syndrome undergoing endovascular repair using a homemade proximal scallop were included.

Patients with zone 2 acute aortic syndrome were considered suitable if the minimum healthy aortic seal length achievable was at least $15 \mathrm{~mm}$ from the expected position of the edge of the scallop, both proximally and laterally. In this series, the proximal neck of the aortic lesion was less than $15 \mathrm{~mm}$ from the LSA. All patients underwent high-resolution computed tomography angiography preoperatively. Demographic, anatomic, intraoperative, and postoperative data were recorded by means of a prospectively maintained database. Follow-up computed tomography angiography was performed at 1 week and 3 and 6 months.

\section{Planning, Sizing, and Device Preparation}

Procedure planning and device sizing were performed using the OsiriX Imaging Software package (version 5.5.2; Pixmeo, Geneva,
Switzerland) with centerline luminal reconstructions. To calculate the length of the scallop, we measured the distance between the left common carotid artery and the distal part of the LSA, which was used as the length of the scallop. We also measured the diameter of the LSA. The diameter of the scallop was that of the LSA with an additional $5 \mathrm{~mm}$ on all sides.

A scallop was fashioned in each standard tubular Valiant Thoracic stent graft (Valiant Captivia; Medtronic Vascular, Santa Rosa, Calif). Stent grafts of sufficient length were selected to enable proximal and distal landing zones in healthy aorta of at least $15 \mathrm{~mm}$. Stent graft diameters in proximal and distal sealing zones were oversized by $10 \%$ to $15 \%$.

Stent graft modifications were performed on a back table, commencing before the start of anesthesia. The stent graft was partially unsheathed while holding the proximal tip capture using the barrel of a 5-mL syringe (Figure 1). The scallop was fashioned to lie on the outer curve of the aortic arch to facilitate easy positioning over the origin of the LSA.

Device modifications were tailored to individual patient anatomy. Scallop margins were outlined on the stent graft fabric using a sterile marking pen such that the diameter was that of the LSA with an additional $5 \mathrm{~mm}$ on all sides. An 11 blade scalpel was used to fashion the scallop. Two lateral radiopaque markers were positioned to delineate the distal and lateral edge of the scallop (Figure 2).

Each radiopaque marker consisted of the loop of a snare (Amplatz GooseNeck, Covidien, Minneapolis, Minn), secured on the fabric with a continuous locking 5-0 polypropylene suture. The modified stent graft was then reloaded in the existing sheath using a temporary vessel loop to collapse each stent. A further 3 -cm radiopaque marker (using the loop of a snare) was sutured with 5-0 polypropylene and part of an incision drape onto the sheath to ensure accurate radiologic positioning of the scallop on the outer curve of the aorta (Figure 3).

\section{Technique}

All procedures were performed under general anesthesia, through a surgical cut-down of the common femoral artery. The Valiant thoracic stent graft was introduced over an ultra-stiff guide wire. Heparin 5000 IU was administered at this point. Angiographic runs were performed through a
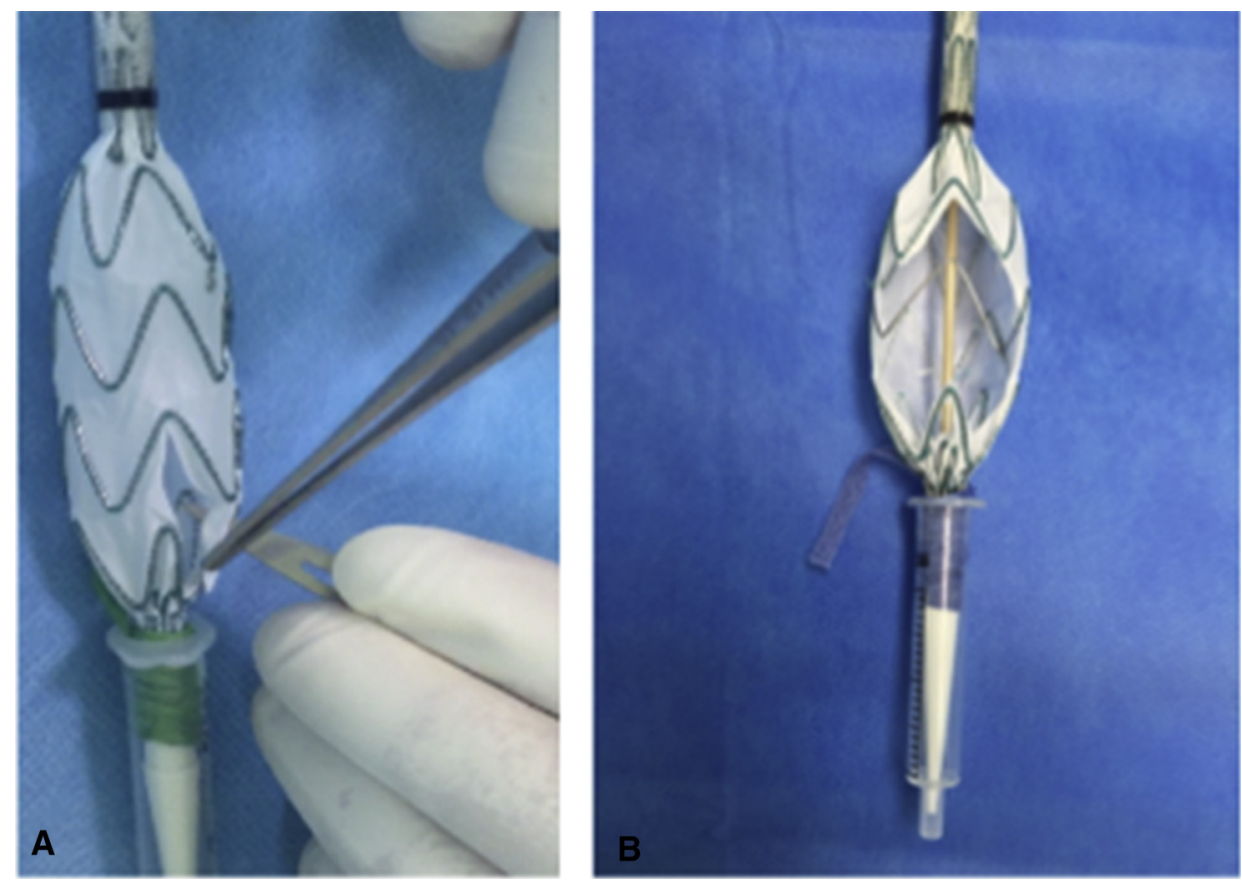

FIGURE 1. A, Valiant (Medtronic Vascular, Santa Rosa, Calif) thoracic stent graft was partially unsheathed. The proximal tip capture was held using a cut 5-mL syringe. The scallop was fashioned using a 11 blade. B, The scallop was fashioned on the upper side of the aortic arch. 

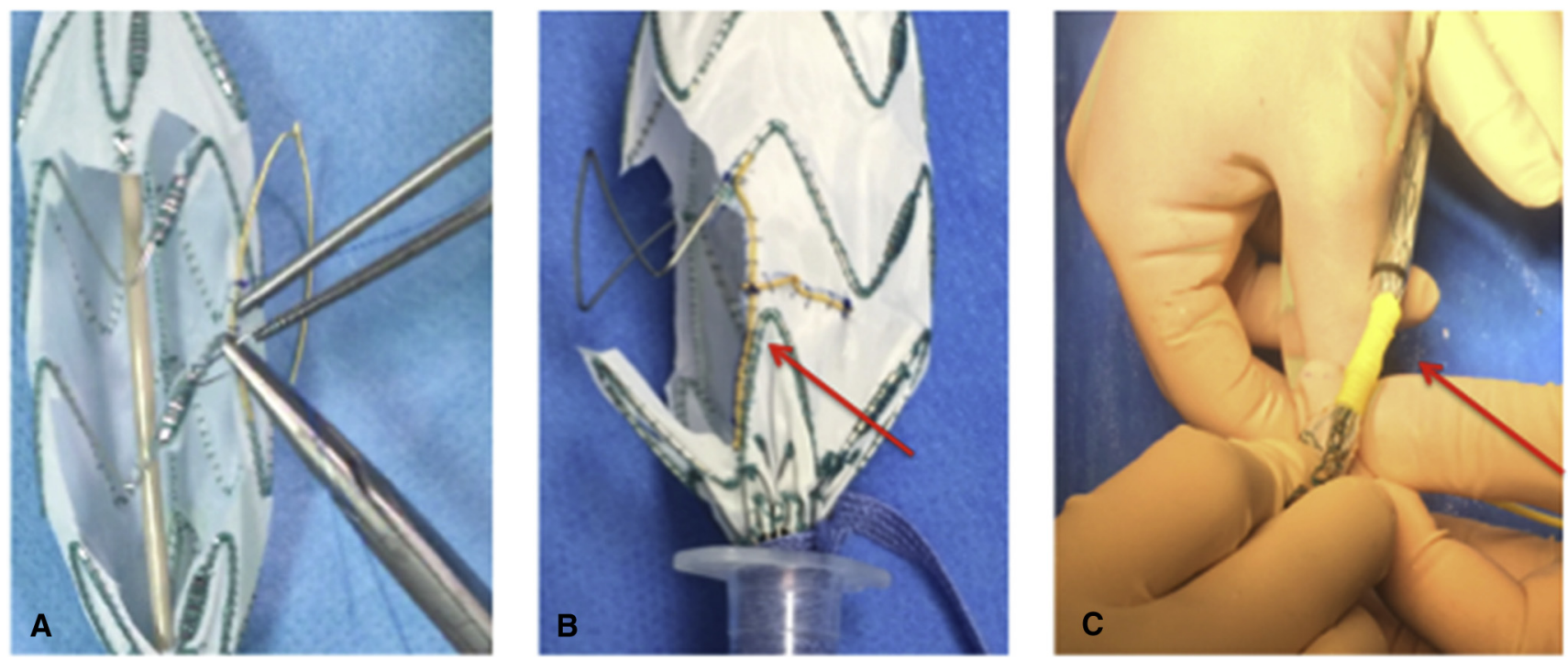

FIGURE 2. A, Two lateral radio-opaque markers were fixed on the fabric with a running locking suture of 5-0. Prolene. B, Two lateral radio-opaque markers were positioned and delineated the distal and lateral position of the scallop. The loop of a snare was used as the raw materials for the radioopaque markers. C, The stent graft was finally reloaded in the existing sheath using a temporary vessel loop to collapse each stent.

pigtail catheter, introduced percutaneously through the contralateral common femoral artery. By using an arch angiogram, the radiopaque marker of the sheath was aligned to the outer curve of the aortic arch. In cases of misalignment, the graft was pulled back to the descending aorta, reoriented, and then readvanced. Mean blood pressure at deployment was lowered to approximately $80 \mathrm{~mm} \mathrm{Hg}$ to optimize accuracy of deployment. An angiogram "opening" the aortic arch was used to align the distal marker of the scallop just distal to the LSA. A perpendicular angiogram also was obtained to aid clock face alignment. The stent graft was adjusted to ensure that the scallop's side markers were positioned on either side of the LSA.

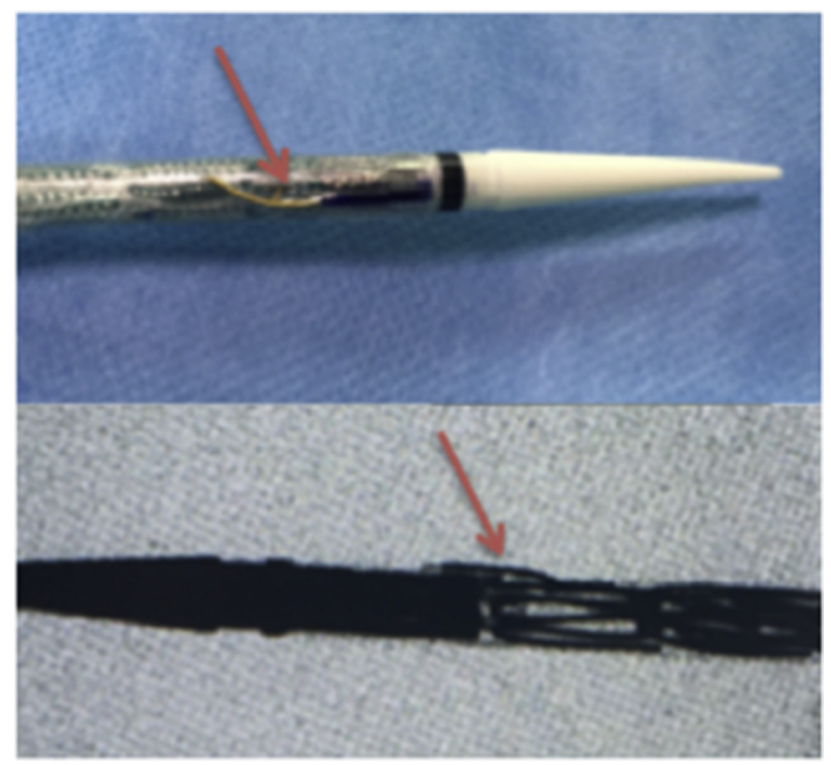

FIGURE 3. A 3-cm in length radio-opaque marker (using the loop of a snare) was fixed by 4 stitches of 5-0 polypropylene and part of an incision drape on the sheath to facilitate radiologic localization of the scallop and positioning on the outer curve of the aorta.
Molding balloon angioplasty within the stent graft was optional. Completion angiograms were performed in all cases.

\section{RESULTS}

Between May 2015 and December 2015, 10 patients underwent urgent or emergency TEVAR in zone 2 for an acute aortic syndrome secondary to unremitting symptoms or rupture. Among them, 8 were treated using a homemade proximal scalloped stent graft to preserve the patency of the LSA. Indications for TEVAR included traumatic transection of the thoracic aorta $(\mathrm{n}=3)$, acute complicated type $B$ aortic dissection $(n=4)$, and subacute complicated type $B$ aortic dissection acute $(n=1)$. Patient demographics are listed in Table 1, and procedural details are described in Table 2.

Median duration for stent graft modifications was $15 \mathrm{mi}-$ nutes (range, 14-17 minutes). A technical success rate of $100 \%$ was obtained with sealing in all cases and no type I endoleaks. All left subclavian arteries were patent (Figures 4 and 5), although 1 case was associated with a $50 \%$ stenosis, which occurred secondary to an excessively laterally positioned scallop. ${ }^{4}$ The median hospital stay was 6 days (3-15 days). Mortality related to aortic repair was $0 \%$. One patient died of the sequelae of traumatic rupture of the left kidney on postoperative day 5 , which was managed conservatively. During a follow-up of $7.2 \pm 2$ months, there were no conversions to open surgical repair or aortic ruptures. No paraplegia, endoleak, retrograde dissection, or other complications related to the aorta were recorded.

\section{DISCUSSION}

This study reports our single-center experience of using a homemade proximal scalloped stent graft for TEVAR of 
TABLE 1. Patient demographics

\begin{tabular}{|c|c|c|c|c|c|}
\hline Patient & Sex & Age, $y$ & Comorbidities & Aortic pathology & Associated lesions \\
\hline 1 & M & 80 & $\begin{array}{l}\text { Hypertension } \\
\text { Chronic obstructive pulmonary disease } \\
\text { Pulmonary embolism }\end{array}$ & Traumatic transection of the thoracic aorta & $\begin{array}{l}\text { Hemothorax } \\
\text { Multiple rib fractures } \\
\text { Fracture of the pelvis } \\
\text { Fracture of the rachis }\end{array}$ \\
\hline 2 & $\mathrm{~F}$ & 65 & $\begin{array}{l}\text { Hypertension } \\
\text { Diabetes mellitus }\end{array}$ & $\begin{array}{l}\text { Acute complicated type B aortic dissection: } \\
\text { Paraplegia }\end{array}$ & \\
\hline 3 & M & 65 & $\begin{array}{l}\text { Hypertension } \\
\text { Esophagectomy }\end{array}$ & $\begin{array}{l}\text { Subacute complicated type B aortic } \\
\text { dissection: Rapid aortic expansion }\end{array}$ & \\
\hline 4 & M & 62 & & Traumatic transection of the thoracic aorta & $\begin{array}{l}\text { Hemothorax } \\
\text { Multiple rib fractures } \\
\text { Rupture of the left kidney }\end{array}$ \\
\hline 5 & M & 59 & Hypertension & $\begin{array}{l}\text { Acute complicated type B aortic dissection: } \\
\text { Rapid aortic expansion }\end{array}$ & \\
\hline 6 & M & 74 & $\begin{array}{l}\text { Hypertension } \\
\text { Chronic renal failure } \\
\text { Diabetes mellitus }\end{array}$ & $\begin{array}{l}\text { Acute complicated type B aortic dissection: } \\
\text { Rapid aortic expansion }\end{array}$ & \\
\hline 7 & M & 69 & Hypertension & Traumatic transection of the thoracic aorta & Fracture of the pelvis \\
\hline 8 & M & 58 & Hypertension & $\begin{array}{l}\text { Acute complicated type B aortic dissection: } \\
\text { Left renal ischemia } \\
\text { Right limb ischemia }\end{array}$ & \\
\hline
\end{tabular}

zone 2 acute aortic syndrome. The use of the homemade proximal scalloped stent graft is a feasible and effective option for maintaining LSA vascularization during TEVAR involving a spectrum of acute thoracic aortic pathology. This approach provides a rapid, reproducible method of scalloping the endograft material. There are special anatomic considerations when using this technique. $\mathrm{Pa}$ tients with zone 2 acute aortic syndrome were considered suitable only if the minimum healthy aortic seal length was at least $15 \mathrm{~mm}$ from the expected position of the edge of the scallop, both proximally and laterally. During the study period, 2 patients with an acute complicated aortic dissection underwent deliberate coverage of the LSA because the proximal entry tear was too close laterally $(<15 \mathrm{~mm})$ to the anticipated position of the edge of the scallop. During the study period, no patients were admitted to our department requiring TEVAR in zone 2 for a ruptured atherosclerotic ulcer, degenerative aneurysms, or chronic

TABLE 2. Procedure details

\begin{tabular}{lccc}
\hline Patient & $\begin{array}{c}\text { Minimal } \\
\text { sealing } \\
\text { length, mm }\end{array}$ & $\begin{array}{c}\text { Stent graft } \\
\text { diameter/ } \\
\text { length, mm }\end{array}$ & $\begin{array}{c}\text { Duration for } \\
\text { stent graft } \\
\text { modifications (min) }\end{array}$ \\
\hline 1 & 15 & $38 / 167$ & 15 \\
2 & 17 & $30 / 167$ & 16 \\
3 & 16 & $34 / 167$ & 15 \\
4 & 15 & $30 / 167$ & 17 \\
5 & 16 & $30 / 167$ & 14 \\
6 & 15 & $38 / 217$ & 15 \\
7 & 15 & $34 / 167$ & 14 \\
8 & 15 & $30 / 167$ & 14 \\
\hline
\end{tabular}

dissection. We believe that this approach may be appropriate for degenerative aneurysm or chronic dissection. We used the Medtronic stent graft because we have extensive experience with this device. Furthermore, it is currently the most conformable of the devices available. The tip capture facilitates accurate deployment. Other devices could be used for the same approach, namely, the Bolton (Bolton Medical, Sunrise, Fla) and the Cook Alpha (Cook Medical, Bloomington, Ind). The deployment system of the Gore device (WL Gore \& Associates, Inc, Flagstaff, Ariz) prevents reloading of the stent graft into the sheath. No patient in this series had an anatomically bovine arch. From a technical point of view, this would only have influenced the diameter of the scallop. We have no concerns regarding the stability of the uncovered portion of the Z-stent with regard to its movement/position during stent graft deployments because the Z-stents are supported on at least $50 \%$ of their length. The main pitfall of the procedure is appropriate positioning of the LSA scallop before deployment. This is facilitated by the addition of a supplementary $3-\mathrm{cm}$ radiopaque marker onto the sheath, allowing accurate radiologic positioning of the scallop on the outer curve of the aorta (Figure 3). A large experience with standard TEVAR and fenestrated grafts for the thoracoabdominal aorta is from our perspective of significant importance.

The paradox of aortic arch geometry is that to achieve an appropriate sealing zone by apposition of the proximal stent graft to the inner curvature, a much longer length needs to be covered in the outer curvature. This is why most failures of TEVAR are caused by proximal type I endoleaks originating from the inner curvature of the aortic arch. The 

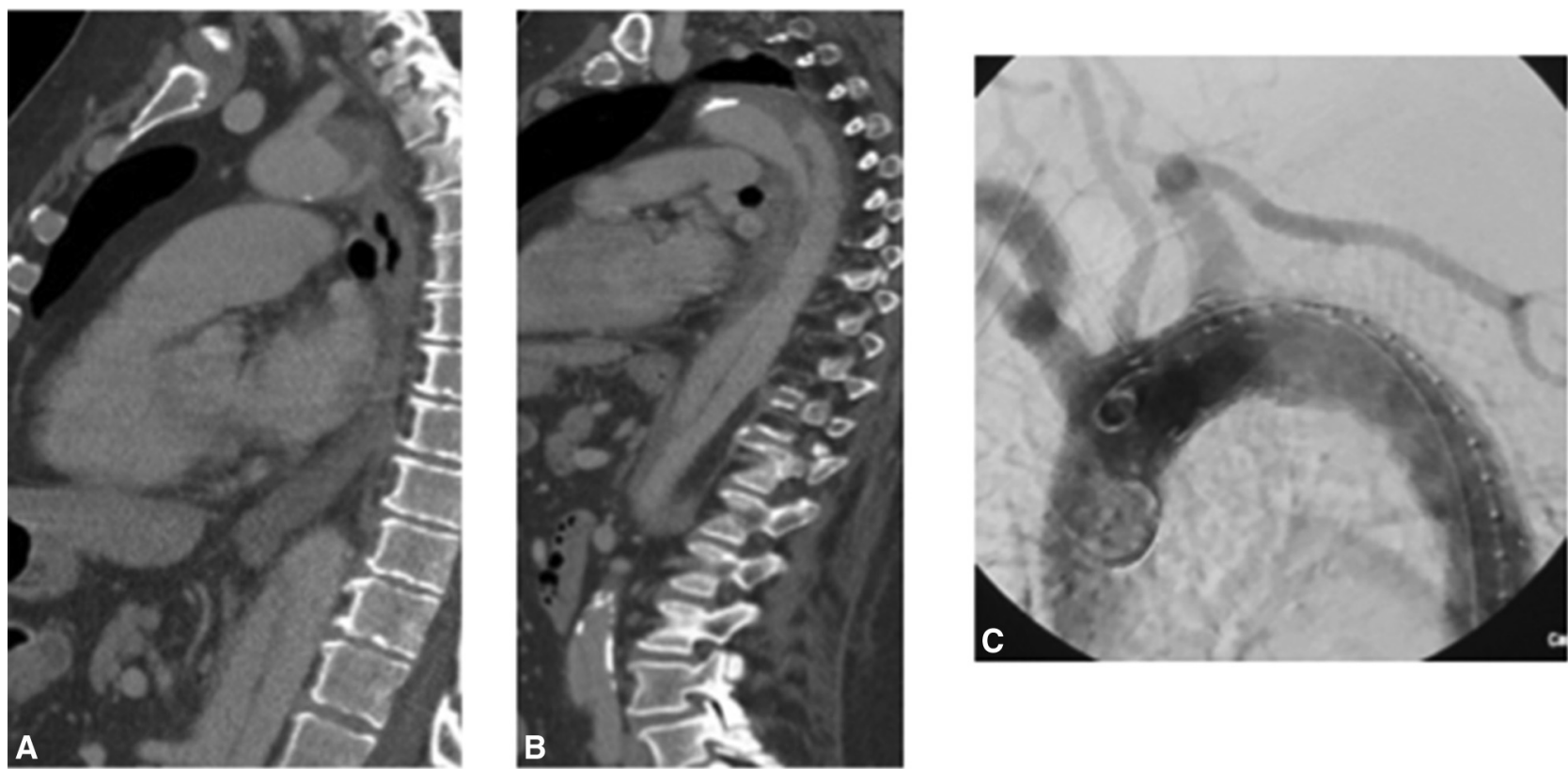

FIGURE 4. A and B, Preoperative computed tomography scan of an acute complicated type B aortic dissection (paraplegia) involving the distal part of the arch. C, Patient treated by homemade scalloped TEVAR with proximal scallop for the LSA. Completion angiography demonstrates the closure of the proximal entry tear and patency of the LSA.

concept of a proximal scallop for TEVAR allows simple extension of the proximal sealing zone along the inner curvature of the aortic arch, while leaving supra-aortic trunks patent on the outer curvature.
There are multiple options available to treat zone 2 acute aortic syndrome. Intentional coverage of the LSA during TEVAR has been performed routinely by some and is thought to be associated with a low risk of clinically
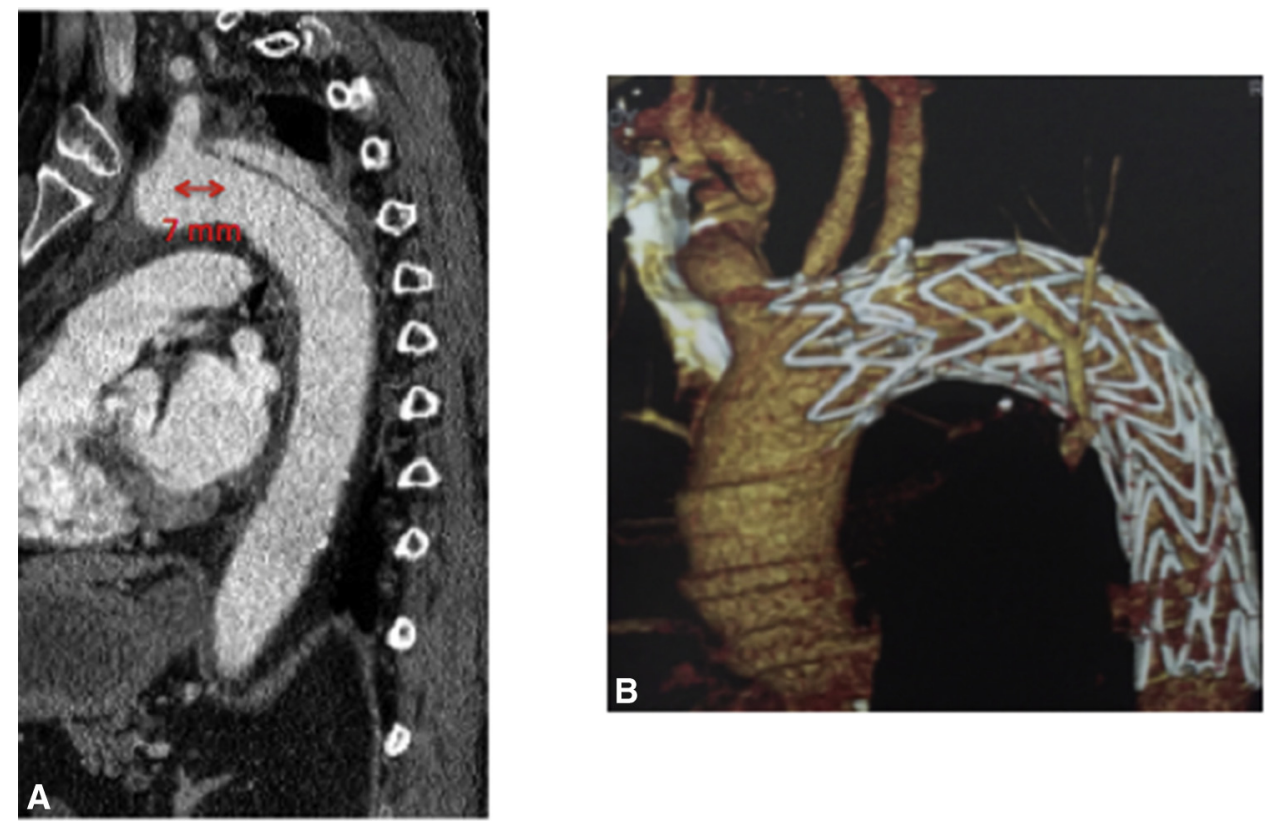

FIGURE 5. A, Preoperative computed tomography scan of an acute complicated type B aortic dissection (rapid aortic expansion) involving the distal part of the arch. The proximal entry tear is $7 \mathrm{~mm}$ distal to the LSA. B, Homemade proximal scallop for the LSA in a patient undergoing TEVAR. Threedimensional reformatted computed tomography angiography demonstrates the closure of the proximal entry tear and patency of the LSA. 
significant complications. However, evidence is mounting that LSA coverage is associated with a significant risk of spinal cord ischemia, vertebral territory stroke, and left upper limb ischemia. ${ }^{2,3}$ In $2009,{ }^{7}$ these findings led to the Society for Vascular Surgery Committee on Aortic Disease to suggest routine preoperative revascularization for planned coverage of the LSA during elective TEVAR. These guidelines did make exceptions in the setting of emergency TEVAR or when other circumstances would preclude preoperative LSA revascularization.

Parallel grafts such as the chimney technique constitute an alternative. Encouraging short-term results have been reported in small series, but type Ia endoleaks through the gutters and uncertainty regarding the long-term patency of visceral artery covered stents remain a concern.

In situ retrograde laser fenestration is a feasible and effective option for LSA revascularization. Redlinger and colleagues $^{6}$ reported 22 patients. Technical success was $100 \%$. No major in situ laser fenestration-related operative complications occurred. However, special attention must be paid to anatomic considerations. The judicious use of multiple $\mathrm{C}$-arm projections before laser fenestrations ensures that the laser fiber is aligned appropriately. Furthermore, the angle of LSA take-off from the aortic arch has a considerable influence on the technical ease and success of laser fenestration.

Other off-the-shelf thoracic branch devices such as the Valiant Mona LSA ${ }^{8}$ (Medtronic Vascular) and the Gore single-side branch (WL Gore \& Associates, Inc) are designed to maintain LSA patency while diverting circulation through the encroaching aneurysm. Although these devices could be used during emergency TEVAR, they are not currently commercially available. Availability of an offthe-shelf branched thoracic stent graft would increase the number of treatable patients. Because the diameter of the scallop was that of the LSA with an additional $5 \mathrm{~mm}$ on all sides, patients with a proximal entry tear in close proximity to the LSA cannot be treated with the approach outlined in this series. This is not a contraindication for branch devices, but their deployment is more challenging.

Studies reporting experience using the custom-made Bolton Relay Plus proximal scalloped thoracic stent graft have provided appealing results for TEVAR of thoracic aortic lesions when dealing with short or angulated proximal necks. ${ }^{9,10}$ However, commercial custom-made devices require at least 6 to 12 weeks to be manufactured, thereby precluding the treatment of patients requiring urgent intervention or expedited treatment.

We acknowledge that the current practice of stent graft modification is controversial. The patients in this series underwent homemade proximal scalloped stent graft on a compassionate-use basis in an urgent or emergency setting.

This case series suggests that promising short-term results can be achieved using a homemade proximal scalloped stent graft in patients presenting with various acute aortic pathologies. The technical success rate is encouraging. The observed perioperative morbidity and mortality after this approach compare favorably to other techniques of LSA revascularization. In the long term, strict surveillance of these stent grafts and modifications will be necessary to monitor and ensure durability of repair because of the potential for stent collapse or stent breakage.

Scalloped TEVAR allows the distal aortic arch to be considered a reliable landing zone when the scallop is for the LSA. More data are required to establish the applicability of this approach to the aortic arch more proximally and to establish durability.

\section{CONCLUSIONS}

The use of a homemade proximal scalloped stent graft is a feasible and effective option for LSA revascularization during TEVAR involving a spectrum of acute thoracic aortic pathology. This approach provides a rapid, reproducible method of fenestrating the endograft material. Durability concerns need to be assessed in additional studies with long-term follow-up.

\section{Conflict of Interest Statement}

Authors have nothing to disclose with regard to commercial support.

\section{References}

1. Clough RE, Mani K, Lyons OT, Bell RE, Zayed HA, Waltham M, et al. Endovascular treatment of acute aortic syndrome. J Vasc Surg. 2011;54:1580-7.

2. Riesenman PJ, Farber MA, Mendes RR, Marston WA, Fulton JJ, Keagy BA. Coverage of the left subclavian artery during thoracic endovascular aortic repair. J Vasc Surg. 2007;45:90-4.

3. Patterson BO, Holt PJ, Nienaber C, Fairman RM, Heijmen RH, Thompson MM. Management of the left subclavian artery and neurologic complications after thoracic endovascular aortic repair. J Vasc Surg. 2014;60:1491-7.

4. Canaud L, Hireche K, Berthet JP, Branchereau P, Marty-Ané C, Alric P. Endovascular repair of aortic arch lesions in high-risk patients or after previous aortic surgery: midterm results. J Thorac Cardiovasc Surg. 2010;140:52-8.

5. Baldwin ZK, Chuter TA, Hiramoto JS, Reilly LM, Schneider DB. Double-barrel technique for preservation of aortic arch branches during thoracic endovascular aortic repair. Ann Vasc Surg. 2008;22:703-9.

6. Redlinger RE Jr, Ahanchi SS, Panneton JM. In situ laser fenestration during emergent thoracic endovascular aortic repair is an effective method for left subclavian artery revascularization. J Vasc Surg. 2013;58:1171-7.

7. Matsumura JS, Lee WA, Mitchell RS, Farber MA, Murad MH, Lumsden AB, et al; Society for Vascular Surgery. The Society for Vascular Surgery Practice Guidelines: management of the left subclavian artery with thoracic endovascular aortic repair. J Vasc Surg. 2009;50:1155-8.

8. Roselli EE, Arko FR III, Thompson MM; Valiant Mona LSA Trial Investigators. Results of the Valiant Mona LSA early feasibility study for descending thoracic aneurysms. J Vasc Surg. 2015;62:1465-7.

9. Ben Abdallah I, El Batti S, Sapoval M, Abou Rjeili M, Fabiani JN, Julia P, et al. Proximal scallop in thoracic endovascular aortic aneurysm repair to overcome neck issues in the arch. Eur J Vasc Endovasc Surg. 2016;51:343-9.

10. Alsafi A, Bicknell CD, Rudarakanchana N, Kashef E, Gibbs RG, Cheshire NJ, et al. Endovascular treatment of thoracic aortic aneurysms with a short proximal landing zone using scalloped endografts. J Vasc Surg. 2014;60:1499-506.

Key Words: physician-modified thoracic stent grafts, thoracic endovascular aortic repair 